\title{
Política educacional e neoliberalismo no
}

\section{Brasil: uma leitura sob a ótica do serviço}

social / Neo-liberalism and educational policy

in brazil: a reading from the perspective of social services

Thalita Giovanna BülL*

Resumo: Este artigo retrata a forma pela qual a política educacional brasileira vem se organizando para atender aos interesses de manutenção da hegemonia do capital. Para tanto, articula processos históricos que demonstram a forte presença de uma cultura política autoritária, que se expressa na condução das políticas públicas ainda hoje. Aponta para a centralidade, porém não exclusividade da educação na superação da sociedade do capital, por meio da construção de um modelo alternativo que contemple as necessidades e expectativas da classe trabalhadora. Indica o trabalho realizado pelos assistentes sociais como um fator fundamental, ainda que não exclusivo, para a construção de uma sociabilidade "para além do capital" (MÉSZÁROS, 2005).

Palavras-chave: política educacional, neoliberalismo, serviço social

Abstract: This article portrays the way the Brazilian educational policy has been organized to serve the interests of maintaining the hegemony of capital. To this end, articulates the historical processes that demonstrate the presence of a strong authoritarian political culture, which is expressed in the conduct of public policy today. Points to the centrality, but not exclusive to education in overcoming society's capital, by building an alternative model that addresses the needs and expectations of the working class. Indicates the work done by social workers as a key factor, though not exclusively, for the construction of a sociability "beyond the capital" (Mészáros, 2005).

Assistente Social. Mestre pela PUC-SP. E-mail: thalitabull@yahoo.com.br. 
Keywords: educational policy, neoliberalism, social service.

\section{Introdução}

Acontece que a história brasileira, particularmente a econômica, 'é antes uma sucessão de episódios muito semelhantes, de ciclos que se repetem monotonamente no tempo e no espaço. E continuam repetindo-se'. Tem-se a impressão de que "o tempo se projetou aqui no espaço". O passado parece não só múltiplo, diversificado, mas presente. (...) A nossa história ainda é, por isso, em muitos casos, uma atualidade (IANNI, 1992, p. 60 - grifos do autor).

$\mathrm{O}$ artigo que ora apresentamos toma como ponto de partida a relação direta entre o serviço social e a política educacional, ressaltando as transformações que ocorreram no cenário brasileiro, principalmente a partir dos anos 1980, em especial no campo da legislação, adequadas aos preceitos neoliberais, sob uma leitura do Serviço Social, enfatizando a centralidade destes profissionais a partir de sua contribuição com o processo educativo realizado.

Assim, partimos do pressuposto de que as mudanças ocorridas na legislação, em especial a promulgação da Lei de Diretrizes e Bases da Educação Nacional (LDB) em 1996 ocasionaram grandes repercussões na organização dos sistemas de ensino por parte dos municípios, como a municipalização do Ensino Fundamental e a transição das creches para a competência da Política de Educação, o que em muitos casos, resultou na transferência de vários profissionais que anteriormente estavam vinculados à Política de Assistência Social para Secretarias Municipais da Educação, entre eles, os assistentes sociais. Entretanto, a nova LDB inaugura também possibilidades para o exercício profissional do assistente social nos diversos níveis de ensino.

Todas essas transformações não ocorreram de maneira ocasional ou por mera vontade de um ou outro grupo da sociedade, mas são frutos de uma determinada relação estabelecida entre os 
interesses de diferentes sujeitos inseridos em uma determinada conjuntura social e histórica, ou nas palavras de Couto (2004, p. 20), são "expressão de um patamar de sociabilidade, estão situados em um campo essencialmente político, porque são resultantes do embate de interesses e ações dos sujeitos sociais".

Assim, torna-se incoerente refletir sobre a atual configuração da política de educação no Brasil sem estabelecer uma relação com o particular processo de desenvolvimento sócio-histórico do país.

Nosso desenvolvimento como nação sempre fora marcado por interesses externos à nossa vontade, tudo o que produzíamos e ainda produzimos teve e ainda tem como objetivo os interesses do consumidor externo, o que favorece o estabelecimento de uma economia subsidiária e dependente.

As respostas oferecidas pelo Estado diante das requisições populares ainda se colocam no plano do atendimento aos interesses externos, de legitimação e perpetuação de um sistema econômico desigual e excludente.

Se vamos à essência de nossa formação, veremos que na realidade nos constituímos para fornecer açúcar, tabaco, alguns outros gêneros; mais tarde ouro e diamante; depois, algodão, e em seguida café, para o comércio europeu. Nada mais que isto. É com tal objetivo, objetivo exterior, voltado para fora do país e sem atenção a considerações que não fossem o interesse daquele comércio, que se organizarão a sociedade e a economia brasileiras. Tudo se disporá naquele sentido: a estrutura bem como as atividades do país (IANNI, 1992, p. 55).

A cultura brasileira foi sendo construída ao longo do tempo como uma sucessão de eventos cíclicos, onde passado e presente parecem misturar-se e confundir nossos olhos. O sentido da colonização permeou não somente o período do Brasil Colônia, mas permanece até hoje, sendo possível afirmar, inclusive, que o Brasil permanece sendo colonizado, apenas o que mudou foi o nome de seu colonizador. "Um século depois da Abolição subsistem heranças 
das formas culturais e de sociabilidade produzidas com o escravismo. E tudo isso está atravessado por um desenvolvimento desigual e combinado caleidoscópico, no qual a geografia e a história se mostram enlouquecidas." (IANNI, 1992, p. 62) Nosso presente está fortemente marcado por vários aspectos do passado, é um Brasil que se mescla entre o velho e o novo, entre o moderno e o antigo.

\section{Cultura brasileira e política de educação}

Desta forma, como podemos pensar sobre a Educação que temos hoje, sem fazer qualquer referência ao "mito fundador" (CHAUÍ, 2007) do Brasil? De que forma esta estrutura organizacional estaria contribuindo ou não para a reprodução deste mito? Como os currículos escolares são planejados de forma a possibilitar uma real compreensão acerca da realidade onde os sujeitos sociais se inserem?

Ainda que não tenhamos por objetivo resgatar cronologicamente a história da educação brasileira, consideramos importante nos reportar a um dos aspectos cruciais desta história, que reflete a relação direta entre a mesma e o processo de desenvolvimento capitalista no país.

Com o adensamento da contradição entre a classe trabalhadora e a burguesia industrial, no início do século XX, a questão social passa a requisitar intervenções estatais mais posicionadas, as quais contam com o apoio de segmentos da burguesia e da Igreja Católica para responder, à sua maneira, às necessidades emanadas da população.

Assim, as primeiras creches são criadas como um dos mecanismos de contenção da classe trabalhadora, no atendimento às suas reivindicações, e utilizadas, ao mesmo tempo, como instrumento de controle ideológico e cultural, com raízes que se encontram em um terreno marcado por relações autoritárias. 
As demandas por atendimento em creches e pré-escolas são entendidas, pelos setores dominantes, como expressões de necessidades individuais, de mulheres cuja adaptação ao novo padrão de produção não se deu de maneira satisfatória, desconsiderando sua essencial vinculação à relação contraditória que se estabelece entre as classes sociais no modo de produção capitalista.

O viés ideológico e moralizante ocultou as raízes sociopolíticas das necessidades sociais e, no caso particular das creches e pré-escolas, fixou o lugar social da mãe operária como o lugar desenraizado da moral e responsável pela formação de crianças propensas a serem problemáticas. As creches seriam, então, um 'mal necessário' um lugar de formação compensatória dos deslizes higienistas e moralistas da então nascente classe operária (NUNES, 2009, p. 87-88).

As respostas oferecidas pelos grupos dominantes às reivindicações populares, sempre tiveram como diretriz principal a tutela e o paternalismo, como expressões de uma cultura autoritária gestada e legitimada na própria história da sociedade brasileira, como um passado que novamente se faz presente.

Ianni (1991, p. 5) aponta como os setores dominantes da sociedade revelam uma certa dificuldade ao posicionar-se diante das reivindicações populares emanadas das desigualdades sociais que afetam as classes subalternas, reagindo muitas vezes de maneira extremamente intolerante "tanto em termos de repressão como de explicação". Para o autor, "essa inclinação é muito forte no presente, mas já se manifestava nítida no passado".

Entretanto, é preciso considerar a educação como um campo de lutas, de disputa pela hegemonia, onde interesses diversos entram em confronto na luta pela manutenção da ordem estabelecida ou pela sua reversão, expressando os conflitos de classe inerentes à sociedade capitalista, conflitos estes claramente expressos no processo que culminou com a promulgação da Constituição Federal de 1988, mas que não se encerrou aí. 
Tal período da história recente, que se inicia no final dos anos 1980, marcado pela promulgação da Carta Constitucional, se arrasta até os dias atuais, carregando consigo a regulamentação de seus direitos sociais.

Trata-se de um tempo fecundo para o avanço no campo da proteção social no país, mas que ao mesmo tempo e contraditoriamente põe em risco as conquistas advindas das lutas travadas pela classe trabalhadora no cenário brasileiro.

Intensifica-se a exploração do trabalho humano na busca incessante pela maximização do lucro, com reflexos diretos nas condições de vida e trabalho de grande parte da população, assim como as relações entre Estado, sociedade civil e mercado passam a ser redefinidas, tendo em vista uma mínima intervenção estatal, de forma a abrir espaço ao livre mercado.

No contexto de crise e de mundialização do capital, o Brasil, a partir da década de 1990, passa a implementar programas de ajuste estrutural e de estabilização econômica para adequar o país à nova ordem econômica. Seguindo as recomendações do Consenso de Washington, os sucessivos governos brasileiros colocaram em curso políticas macroeconômicas de estabilização e reformas estruturais liberalizantes (FIORI, 1996) centradas na abertura comercial, financeira, produtiva e tecnológica. Além disso, promoveram a estabilização monetária ancorada no dólar, a política de privatização, a reforma do Estado e a desregulamentação do mercado de trabalho (ALENCAR, 2008, p. 65).

Verifica-se aí, uma tensa contradição que se estabelece nesse período. De um lado o Brasil experimenta, após longos anos de regime ditatorial, um processo democrático de reabertura política, com eleições diretas e a aprovação da chamada Constituição Cidadã, que ampliava e garantia os direitos civis, políticos e sociais ao povo.

De outro lado, avança a hegemonia do receituário neoliberal, incentivando aos países não desenvolvidos a adesão às normas propagadas pelo Consenso de Washington, enquanto estratégia de 
desenvolvimento e crescimento econômico dos mesmos, e que no caso brasileiro, contrapunham-se aos princípios orientadores da referida Constituição.

Embora tal contradição tenha um peso importante para a (re)construção da democracia no país, é importante destacar o avanço nas conquistas populares, principalmente do ponto de vista da participação no processo, o que aponta para "a compreensão de que novos tempos foram inaugurados no Brasil”, com a abertura de ao menos "duas forças centrais no Congresso Nacional, uma representada por partidos de esquerda, comprometidos com a viabilidade das reformas sociais, e outra representada pelos partidos conservadores, à qual foi dado o nome de 'Centrão"' (COUTO, 2004, p. 155).

Tais forças “de esquerda” foram, em grande parte, responsáveis pelas inúmeras conquistas que favoreciam as camadas populares, e se constituíam através de associações e entidades de classe profissionais, partidos políticos com orientações progressistas, movimentos sociais, sindicatos, entre outros grupos cujos interesses mais amplos coadunavam entre si.

Como resultado das lutas travadas por estes grupos, muitas das reivindicações foram contempladas no texto constitucional, com destaque para o campo dos direitos sociais. Para Couto (2004, p. 158) é no campo dos direitos sociais que estão contidos os maiores avanços da Constituição de 1988.

De acordo com a Carta Constitucional, já em seu art. $6^{\circ}$, a educação aparece inscrita como um dos direitos sociais, juntamente com a saúde, a alimentação, o trabalho, a moradia, o lazer, a segurança, a previdência social, a proteção à maternidade e à infância, e a assistência aos desamparados.

Tal inserção constitui um importante aspecto ao se pensar sobre o trabalho do assistente social na área da educação escolarizada, 
uma vez que se configura enquanto conquista das camadas populares no sentido de responsabilização do Estado perante o aprofundamento das desigualdades sociais no país.

Art. 205. A educação, direito de todos e dever do Estado e da família, será promovida e incentivada com a colaboração da sociedade, visando ao pleno desenvolvimento da pessoa, seu preparo para o exercício da cidadania e sua qualificação para o trabalho (BRASIL, 1988).

Os avanços trazidos pela Constituição de 88 foram extremamente significativos, como já afirmamos, para o campo dos direitos sociais.

$\mathrm{Na}$ educação, a garantia da universalidade, com iguais condições de acesso e permanência, a obrigatoriedade do Ensino Fundamental para todos, inclusive aos que não tiveram acesso na idade própria, o atendimento especializado às pessoas com deficiência sendo realizado preferencialmente na rede regular de ensino, os programas suplementares de atendimento ao aluno por meio de material didático, transporte, alimentação e assistência à saúde, a garantia dos padrões de qualidade e gestão democrática das escolas tiveram um papel fundamental na organização do atual modelo de ensino do país.

Entretanto, se a Constituição Federal de 88 incorporou em seu texto grande parte das reivindicações e lutas populares no que diz respeito à educação, principalmente a universalidade, ela também expressa em um movimento contraditório, assim como a LDB, a lógica dos interesses burgueses, expressos através de um véu neoliberal que a recobre, repercutindo inclusive na forma de organização dos sistemas de ensino, na possibilidade (e até incentivo) à modalidade de ensino a distância, na reiteração do Ensino Fundamental como etapa prioritária de ensino, conforme será especificado adiante.

Nesse projeto [neoliberal], a intervenção na educação com vistas a servir aos propósitos empresariais e industriais tem duas dimensões principais. De um lado, é central, na reestruturação buscada pelos ideólogos neoliberais, atrelar a educação institucionalizada aos objetivos 
estreitos de preparação para o local de trabalho. No léxico liberal, trata-se de fazer com que as escolas preparem melhor seus alunos para a competitividade do mercado nacional e internacional. De outro, é importante também utilizar a educação como veículo de transmissão das ideias que proclamam as excelências do livre mercado e da iniciativa. Há um esforço de alteração do currículo não apenas como objetivo de dirigi-lo a uma preparação estreita para o local de trabalho, mas também com o objetivo de preparar os estudantes para aceitar os postulados do credo liberal (SILVA, 1997, p. 12).

Dito de outra forma, o texto constitucional pode ser entendido como expressão das lutas da classe trabalhadora e dos movimentos sociais em presença naquele momento, assim como das resistências dominantes, tratando-se da mais pura expressão da correlação de forças presentes na década de 1980.

Assim, reafirmamos que o processo de desenvolvimento histórico do Brasil encontra-se impregnado por um presente que insiste em não romper com a dominação do capital sobre todas as esferas da vida cotidiana, é uma história de avanços e retrocessos, marcada fundamentalmente pela exploração de uma classe sobre a outra, através da expropriação do trabalho alheio, cujas bases começam a ser construídas há mais de 500 anos, com a utilização da força de trabalho indígena como forma de enriquecimento da Coroa Portuguesa, e posteriormente com a utilização do tráfico de escravos africanos.

Trata-se de uma sociedade essencialmente patriarcal, estruturada conforme a predominância do poder e do autoritarismo dos homens sobre as mulheres, do Estado sobre o povo, do superior sobre o inferior.

As repercussões dessas características se expressam claramente na política social e, particularmente, na forma pela qual a política de educação se organiza atualmente, no aparato institucional e na legislação que a orienta, na disposição arquitetônica das instituições onde a mesma se materializa, nos conteúdos curriculares transmitidos 
aos educandos, na formação dos profissionais que atuam neste âmbito, nos processos de avaliação etc.

É inegável a posição estratégica que a política de educação tem ocupado na sociedade brasileira, principalmente no que diz respeito à intervenção do Estado na condução das políticas públicas, com destaque àquelas de corte social.

É inegável, também, que esta centralidade tem expressado, em seu limite, um determinado patamar de sociabilidade, no qual as permanentes transformações na esfera produtiva vêm requerendo, ao mesmo passo, transformações na formação dos trabalhadores, enquanto forma de atendimento às novas exigências do mercado, assim como a formulação de estratégias que garantam a hegemonia de um padrão cultural, no sentido de conferir adesão e legitimidade a este novo modo de produção.

Assim, reconhecendo a contradição fundamental que caracteriza este importante campo da política social, a educação tem sido utilizada como uma das alternativas importantes no sentido de oferecer respostas a estas requisições, qualificando o quadro de pessoal conforme as necessidades impostas pelo capital e garantindo as condições necessárias para sustentação e consolidação das constantes alterações realizadas na base econômica da sociedade, relacionando diretamente educação e cultura.

A educação é requisitada, então, como um dos instrumentos de difusão da uma cultura dominante, com o objetivo de reproduzi-la e conservá-la, mostrando que o modo capitalista de produzir é também o modo capitalista de pensar, e dele não se separa (MARTINS, 1978).

Ressaltamos, entre outros aspectos, o fato da política educacional ser a responsável pela administração e disseminação, em última instância, do acúmulo científico e tecnológico, dos conhecimentos, ideias e valores de uma dada sociedade. Embora não se restrinja ao campo educacional, 
nem tampouco à formação escolar, é nesta dinâmica, principalmente nas sociedades modernas, que a cultura, com seus mecanismos de elaboração e difusão, se processa de forma a estabelecer diferenças significativas entre os grupos sociais que a ela tem acesso (ALMEIDA, 2000, p. 65).

Neste caso, enfatizamos a relação entre cultura e educação no marco dos processos culturais que acompanham as transformações na esfera da produção, enquanto partes constitutivas e necessárias das mudanças em curso (ALMEIDA, 2000a).

Os aspectos característicos da cultura brasileira que foi sendo desenhada durante a história do "desenvolvimento desigual e combinado" (IANNI, 1992) do país, passando pelo período colonial, imperial e republicano, conforme já mencionado, ainda se revela, articulada a peculiaridades do atual estágio de desenvolvimento do capitalismo no Brasil.

O próprio processo pelo qual a LDB foi aprovada é clara expressão da cultura autoritária que, apesar do fim do regime militar ditatorial, ainda persiste nos meandros da sociedade brasileira.

Prova recente desta feição autoritária foi o processo de aprovação da Nova Lei de Diretrizes e Bases da Educação - Lei n ${ }^{\circ}$ 9.394, de dezembro de 1996 - que, após anos de discussão (1989-1994) resultou numa proposta aprovada na Câmara que, em 1995, foi engavetada e substituída por outra no Senado, a partir da relatoria do então senador Darcy Ribeiro. O projeto final desconsiderou todo o esforço empreendido pela sociedade civil e pelo Fórum Nacional de Educação, evidenciando de modo inquestionável esta marca excludente e elitizada de nossa cultura política (ALMEIDA, 2000a, p. 63).

Porém, estas alterações pelas quais vem passando a política educacional precisam ser entendidas a partir de sua inserção em uma dinâmica mais ampla, que responde não somente pela reorganização da produção, mas pelo próprio desenvolvimento do capitalismo no contexto de sua reprodução em nível mundial, possibilitando que organismos internacionais passem a ditar regras para aqueles países 
considerados em desenvolvimento, organizando novas bases para a relação entre sociedade e Estado, a quem fica reservado um papel subsidiário na condução político-econômica do país.

Situada num contexto de emergência do projeto neoliberal, a política de educação sucumbe à ordem do capital e à necessidade de manutenção desse sistema.

O Consenso de Washington1 (1989) provocou uma alteração nas formas de organização do Estado e criou uma espécie de manual para os países em desenvolvimento, orientando ações de privatização, terceirização, redução de gastos públicos, entre outras ações que visam alargar a atuação do mercado e reduzir cada vez mais a intervenção estatal. Perry Anderson faz uma análise bastante adequada acerca da atualidade do neoliberalismo.

Economicamente, o neoliberalismo fracassou não conseguindo nenhuma revitalização básica do capitalismo avançado. Socialmente, ao contrário, o neoliberalismo conseguiu muitos dos seus objetivos, criando sociedades marcadamente mais desiguais, embora não tão desestatizadas como queria. Política e ideologicamente, todavia, o neoliberalismo alcançou êxito num grau com o qual seus fundadores provavelmente jamais sonharam, disseminando a simples ideia de que não há alternativas para os seus princípios, que todos, seja confessando ou negando, têm que adaptar-se a suas normas (ANDERSON, 2007, p. 8).

Estas tendências de reordenamento em virtude do ajuste neoliberal, proliferadas principalmente a partir dos anos 1990 e que tiveram impactos significativos em várias áreas, colocaram a política educacional brasileira em um novo ciclo de adequação aos interesses do capital. As reformas introduzidas neste campo deixam clara a

\footnotetext{
"A noção de consenso de Washington se refere, em última instância, a um conjunto de instituições financeiras como o FMI, o Banco Mundial, o BID, o Export-Import Bank, etc., todas elas localizadas em Washington (às vezes poucos quarteirões de distância entre si como o Banco Mundial e o BID) e que seguem a mesma lógica e economia política neoliberal, propugnando o modelo de ajuste estrutural e de estabilização" (TORRES, 2007, p. 109). Trata-se de um receituário elaborado em 1989, composto por dez regras básicas que seguem a lógica do neoliberalismo e recomendado aos países em desenvolvimento, como estratégias para aceleração de seu crescimento econômico e superação das constantes crises estruturais do capital.
} 
posição do governo brasileiro quanto às propostas apresentadas pelo Consenso de Washington, contendo seus gastos na área pública e passando a defender a ideia de livre mercado, inclusive no que diz respeito às políticas sociais, com destaque para a educação.

Segundo Almeida (2000c, p. 157) a ação do Banco Mundial tem como pano de fundo a garantia, por meio de financiamentos diretos e da reorientação dos recursos públicos internos, da inserção dos países periféricos, como é o caso do Brasil, em uma nova ordem mundial, orientada por novos padrões de consumo, sobretudo os de bens culturais, ao mesmo tempo em que estes se tornam produtores de mão de obra minimamente qualificada, que atenda aos deslocamentos contínuos das unidades produtivas, em busca de melhores condições de acumulação de capital.

Ainda de acordo com Almeida (2000b, 2000c) a aprovação da LDB em 1996 representou um marco nas mudanças ocorridas no âmbito da política pública de Educação, estabelecendo um novo projeto educacional para o país, adequado a um projeto societário cujos objetivos estão centrados no ajuste da educação escolarizada às necessidades sociais, técnicas e político-ideológicas da atual fase de expansão do capitalismo.

Logo em seu art. $1^{\circ}$, a referida Lei apresenta uma concepção ampliada de Educação, entendendo que a mesma "abrange os processos formativos que se desenvolvem na vida familiar, na convivência humana, no trabalho, nas instituições de ensino e pesquisa, nos movimentos sociais e organizações da sociedade civil e nas manifestações culturais".

Entretanto, já define que seu conteúdo está restrito somente ao campo da educação escolarizada, apontando que a mesma deve estar vinculada ao "mundo do trabalho e à prática social" (BRASIL, 1996).

Art. $2^{\circ}$. A educação, dever da família e do Estado, inspirada nos princípios de liberdade e nos ideais de solidariedade humana, tem por 
finalidade o pleno desenvolvimento do educando, seu preparo para o exercício da cidadania e sua qualificação para o trabalho. (BRASIL, 1996 - grifos nossos).

Dentro desta concepção, a Constituição Federal de 1988 também já determinava em seu art. $5^{\circ}$ que a educação é direito de todos e dever do Estado e da família, devendo ser promovida e incentivada com a colaboração da sociedade, visando ao pleno desenvolvimento da pessoa, seu preparo para o exercício da cidadania e sua qualificação para o trabalho.

É possível perceber, tanto no texto constitucional quanto na LDB, a concepção e finalidade da política pública de educação, no sentido de qualificar as pessoas para o exercício da cidadania e para o mundo do trabalho, reforçando a ideia de que, os ajustes aos quais vem sendo submetida respondem pela necessidade de adaptação ao novo modelo de acumulação capitalista.

Com a promulgação de Lei de Diretrizes e Bases da Educação Nacional em 1996, o Ensino Fundamental, a Educação Infantil e o Ensino Médio passam a constituir a educação básica. ${ }^{2}$ Neste sentido, são integrantes dos sistemas municipais de ensino, sendo reforçada a priorização do primeiro em detrimento aos demais, ${ }^{3}$ deixando clara, mais uma vez, a intenção em efetivar uma política focalizada na área mais significativa para a manutenção da ordem instituída: o Ensino Fundamental.

O Programa das Nações Unidas para o Desenvolvimento ${ }^{4}$ (Pnud) tem sido um bom exemplo da forma adotada pelos

\footnotetext{
2 "Art. 22. A educação básica tem por finalidade desenvolver o educando, assegurar-lhe a formação comum indispensável para o exercício da cidadania e fornecer-lhe meios para progredir no trabalho e em estudos posteriores" (LDB, 1996).

3 A Emenda Constitucional 14, de 1996 assegura a focalização nesta etapa através da destinação prioritária de recursos ao Ensino Fundamental através da criação do Fundo de Manutenção e Desenvolvimento do Ensino Fundamental e de Valorização do Magistério (Fundef).

4 Segundo o site do Pnud "é a rede global de desenvolvimento da Organização das Nações Unidas, presente em 166 países. Seu mandato central é o combate à pobreza. Trabalhando ao lado de governos, iniciativa privada e sociedade civil, o Pnud conecta países a conhecimentos, experiências e recursos, ajudando pessoas a construir uma vida digna e trabalhando conjuntamente nas soluções traçadas pelos países-membros para fortalecer capacidades locais e proporcionar acesso a seus recursos humanos, técnicos e financeiros, à cooperação externa e à sua ampla rede de
} 
organismos internacionais para ditar prioridades para a política interna principalmente dos países de economia dependente. Estabelece como um dos Objetivos de Desenvolvimento do Milênio (ODM) “atingir o ensino básico universal", tendo como meta brasileira "garantir que, até 2015 , as crianças de todas as regiões do país, independentemente de cor/raça e sexo, concluam o Ensino Fundamental".

Referenciando tais propostas, o Estado brasileiro vem construindo políticas educacionais que buscam alinhar suas metas com os objetivos daquelas instituições, insistindo nas parcerias, com forte apelo ao voluntariado, destituindo-se de suas próprias responsabilidades, incorporando, inclusive, terminologias próprias do ideário neoliberal, onde conceitos como direitos, equidade, diversidade e acesso são substituídos por metas, índices de produtividade, eficiência e qualidade.

Usuários ou sujeitos da ação profissional são transformados em clientes, a equipe passa a ser dividida em liderança e força de trabalho, o processo de trabalho passa a ser guiado por metas, as instituições que compõem a rede de atendimento são denominadas fornecedores e o Projeto ÉticoPolítico se desdobra em missão, visão e valores (BULL, 2010, p. 95).

Assim, em seu art. $9^{\circ}$, a Lei de Diretrizes e Bases da Educação determina a incumbência de elaborar o Plano Nacional de Educação à União, com a colaboração dos estados, Distrito Federal e municípios, apontando em seu art. 87 que o referido Plano deverá estar em consonância com a Declaração Mundial sobre Educação para Todos (1990), resultando em prioridades que se referem à garantia do Ensino Fundamental obrigatório somente para crianças entre 7 e 14 anos, inclusive àquelas pessoas que não tiveram oportunidade de acesso na idade própria, cabendo aos demais níveis de ensino um caráter suplementar, cuja ampliação do atendimento seria realizada de maneira progressiva, porém, sem garantias ou obrigatoriedades.

parceiros. Em 2000, líderes mundiais assumiram o compromisso de alcançar os Objetivos de Desenvolvimento do Milênio, que incluem reduzir a pobreza extrema pela metade até 2015" (Fonte: www.pnud.org.br). 
Outras medidas vêm sendo adotadas nesse sentido. Podemos citar também o Programa Nacional de Inclusão de Jovens - ProJovem Urbano, vinculado à Secretaria Geral da Presidência da República, através da Secretaria Nacional de Juventude. O ProJovem Urbano, destinado a jovens entre 18 e 29 anos que não concluíram o Ensino Fundamental, busca elevar os índices de escolaridade dessa população por meio de um ciclo de formação com duração de 18 meses, sendo que ao final do período, o jovem recebe a certificação de conclusão do Ensino Fundamental e qualificação profissional conforme a área escolhida, dentre as opções oferecidas pelo Programa.

Esta priorização do Ensino Fundamental como área estratégica de investimentos tem expressado um esforço do governo brasileiro em seguir as recomendações dos organismos internacionais, inclusive ampliando o tempo destinado a este nível, conforme a Lei $\mathrm{n}^{\circ} 11.274 / 06^{5}$ e a resolução do Conselho Nacional de Educação (CNE) $\mathrm{n}^{\circ} 03 / 05 .^{6}$

Os anseios da população e dos movimentos sociais envolvidos nesta área vão sendo substituídos pela lógica do mercado, sob o discurso da incompetência administrativa do Estado; pela instalação de um clima de competição entre as instituições educacionais as quais passam a integrar rankings que as classificam entre as melhores e as piores; pela mercantilização do ensino, que passa a ser negociado entre consumidores e prestadores de serviço, e pela consequente inversão da lógica do acesso, onde a classe trabalhadora, historicamente explorada pelo anseio de acumulação capitalista não consegue ingressar na universidade pública, pois o ensino público que lhe foi oferecido até então, encontra-se precarizado e sem condições de preparar-lhe adequadamente para os concorridos vestibulares.

\footnotetext{
A Lei n ${ }^{\circ} 11.274 / 06$ estabelece a ampliação da duração do ensino fundamental para 9 anos, com matrícula obrigatória, iniciando-se aos 6 anos de idade, sendo estipulado o prazo de até 2010 para a efetivação desta alteração.

6 A Resolução 03/05 do CNE estabelece as normas para a ampliação do tempo de duração do Ensino Fundamental, indicando inclusive a nova nomenclatura a ser adotada para esta etapa (anos iniciais e anos finais).
} 
Instala-se um sistema de avaliação onde a responsabilidade pela qualidade da formação, tanto superior quanto fundamental e médio, recai sobre o próprio aluno, sujeito deste processo, incorrendo em um caráter contraditório, que não qualifica o ensino daquelas instituições com baixo desempenho, ao contrário, as mesmas passam a ser punidas e estigmatizadas.

O filósofo marxista István Mészáros, em seu livro A educação para além do capital (2005), tece duras críticas à forma como a educação vem se organizando, defendendo uma ruptura no modo como ela atende ao modo de produção capitalista, que prepara as pessoas para o mercado e não para a vida.

Inicia deixando claro que uma "educação para além do capital" não é possível sem pensarmos em uma transformação profunda, estrutural, na perspectiva de uma outra ordem societária, ou seja, "uma mudança que nos leve para além do capital, no sentido genuíno e educacionalmente viável do termo” (MÉSZÁROS, 2005, p. 25).

Assim, se pretendemos alcançar uma alternativa educacional significativamente diferente, as mudanças não podem ocorrer apenas no nível das formalidades, buscando apenas ajustes ou remendos, uma vez que a própria natureza do capital é irreformável, mas devemos buscar a transformação na essência, na ruptura com a lógica do capital. Para ele:

A educação institucionalizada, especialmente nos últimos 150 anos, serviu - no seu todo - ao propósito de não só fornecer os conhecimentos e o pessoal necessário à máquina produtiva em expansão do sistema do capital, como também gerar e transmitir um quadro de valores que legitima os interesses dominantes, como se não pudesse haver nenhuma alternativa à gestão da sociedade, seja na forma 'internalizada' (isto é, pelos indivíduos devidamente 'educados' e aceitos) ou através de uma dominação estrutural e uma subordinação hierárquica e implacavelmente impostas (MÉSZÁROS, 2005, p. 35).

A educação teria, então, a função de operar na reprodução da força de trabalho e ao mesmo tempo interferir no processo de 
reprodução do "modo capitalista de pensar" (MARTINS, 1978), inculcando valores e ideias nos indivíduos desde cedo, ou seja, quando passam a frequentar a escola, as crianças já começam a ser preparadas para seu inevitável destino: a inserção no mundo do trabalho.

Mészáros (2005) indica, então, como a "internalização" de valores e ideias na perspectiva da dominação foram substituindo a utilização da brutalidade e da violência para assegurar a reprodução do sistema do capital.

Aqui a questão central, sob o domínio do capital, é assegurar que cada indivíduo adote como suas próprias as metas de reprodução objetivamente possíveis do sistema. Em outras palavras, no sentido verdadeiramente amplo do termo educação, trata-se de uma questão de 'internalização' pelos indivíduos (...) da legitimidade da posição que lhes foi atribuída na hierarquia social, juntamente com suas expectativas 'adequadas' e as formas de conduta 'certas', mais ou menos explicitamente estipuladas nesse terreno (MÉSZÁROS, 2005, p. 44).

Entretanto, afirma que "as instituições formais de educação certamente são uma parte importante do sistema global de internalização. Mas apenas uma parte” (MÉSZÁROS, 2005, p. 44).

Independente de participarem das instituições formais de educação, os indivíduos são induzidos a aceitarem os princípios orientadores dominantes e a sobreporem a perspectiva mercantilizada da sociedade acima de suas próprias aspirações pessoais. E afirma que “apenas a mais consciente das ações coletivas poderá livrá-los dessa grave e paralisante situação” (MÉSZÁROS, 2005, p. 45).

Deste modo, já que a educação formal não é a única responsável pela consolidação do "modo capitalista de produzir e de pensar" ela também não pode ser a única responsável pela ruptura com essa lógica.

É preciso reconhecer os limites institucionais que a colocam nessa situação e entendê-la enquanto instituição contraditoriamente inserida nas relações capitalistas, de onde emerge a dificuldade 
estrutural em romper com a lógica do capital, na perspectiva da sobrevivência humana.

E por isso, Mészáros (2005, p. 45) afirma que "no âmbito educacional, as soluções 'não podem ser formais; elas devem ser essenciais'. Em outras palavras, eles devem abarcar a totalidade das práticas educacionais da sociedade estabelecida”.

É necessário desmascarar a ideologia de um certo discurso neoliberal, chamado às vezes de modernizante que, falando do tempo histórico atual, tenta convencer-nos de que a vida é assim mesmo. Os mais capazes organizam o mundo, produzem; os menos, sobrevivem. E que "essa conversa de sonho, de utopia, de mudança radical" só faz atrapalhar a labuta incansável dos que realmente produzem. Deixemo-los trabalhar em paz sem os transtornos que nossos discursos sonhadores lhes causam e um dia se terá uma grande sobra a ser distribuída. Esse inaceitável discurso contra a esperança, a utopia e o sonho é o que defende a preservação de uma sociedade como a nossa, que funciona para um terço de sua população, como se fosse possível aguentar por muito tempo tamanho descompasso (FREIRE, 1997, p. 54).

Assim, a forma pela qual vem se organizando a política educacional, sob a forte influência de uma cultura neoliberal e assentada na lógica da privatização dos serviços públicos e do caráter subsidiário conferido ao Estado, contribui, sem dúvidas, para agravar a situação de desigualdade social existente no país e que, no campo educacional, tende a se refletir em desigualdades no acesso e na permanência nas instituições educacionais, além da impossibilidade de que a classe trabalhadora possa se apropriar deste espaço enquanto locus para construção de sua própria cultura, de seu viver histórico e de seu reconhecimento como sujeitos políticos que são.

Para Almeida (2000a, p. 65) "A luta pelo acesso à escola é, portanto, também a luta pelo acesso a certas condições de elaboração de uma cultura própria dos diversos segmentos sociais".

Torna-se crucial a relação que se estabelece entre a particularidade da política educacional e o exercício profissional dos assistentes sociais 
neste campo contraditório da política social, no sentido de contribuir com a criação de formas estratégicas de resistência a estas expressões da dominação e do autoritarismo burguês que incidiram e ainda incidem nesta área, reconhecendo sua possibilidade em se constituir um espaço de lutas pela construção de uma nova cultura.

Assumimos, assim, a educação como uma forma de enfrentamento das expressões da questão social; enfrentamento, este, que deve ser entendido não apenas como aquisição de conhecimentos para inserção no mercado produtivo, na ótica da empregabilidade, mas sim, como um mecanismo de ruptura com a lógica de produção e reprodução da sociedade capitalista, no sentido de construção de sociabilidades "para além do capital" (MÉSZÁROS, 2005).

Deste modo, considerando tal referencial de Educação, partimos do pressuposto de que o assistente social pode - e deve - oferecer sua contribuição com todo o processo educativo que se expressa no ambiente escolar no sentido de construção de sociabilidades que superem as formas de exploração e dominação exercidas pelo capital.

\section{Últimas palavras}

O processo histórico de formação social do Brasil sempre esteve acompanhado por uma cultura política autoritária, a qual esteve presente em todas as etapas do desenvolvimento histórico do país, em uma sucessão de eventos cíclicos, onde passado e presente se misturam, determinando as formas pelas quais se organiza o Estado brasileiro, como uma forma de garantir a reprodução das relações hierárquicas e de naturalização da divisão da sociedade em classes.

Assim, o "mito fundador" (CHAUÍ, 2007) explica boa parte da sociedade que temos hoje, o modo pelo qual Estado e sociedade se organizam e se relacionam, de forma a perpetuar a existência do mito. 
Uma representação social que atende, como sempre atendeu, aos interesses dominantes, daqueles que detêm o poder, não só dentro, como fora do país e que busca se fortalecer através de um "culto à autocracia burguesa" (FERNANDES, 1975).

Salientamos então as formas pelas quais essas características vêm sendo evidenciadas, neste caso em particular, no âmbito da educação, por meio da implantação de programas de ajustes estruturais, orientados pelo Consenso de Washington como forma de adequar o país à nova lógica mundial, culminando na formulação de um novo projeto educacional no país, em consonância com os interesses de manutenção da hegemonia do capital internacional, cuja expressão máxima foi a promulgação da LDB em 1996, porém nela não se encerra.

Deste modo foi possível compreender que, contraditoriamente, as mudanças ocorridas na legislação, em especial a promulgação da LDB em 1996, ocasionaram grandes repercussões na organização dos sistemas de ensino por parte dos municípios, resultando na transferência de vários profissionais que anteriormente estavam vinculados à Política de Assistência Social para Secretarias Municipais da Educação, entre eles, os assistentes sociais, abrindo um leque de possibilidades para o exercício profissional nesta área, ultrapassando a Educação Infantil, mas incluindo também os demais níveis de ensino.

Assim, a entrada dos assistentes sociais no campo da educação pública, foi fortemente influenciada pelos processos sociais em curso no país naquele determinado momento histórico, os quais permanecem repercutindo nas condições e no exercício profissional neste campo.

Entretanto, com este artigo deixamos claro que, apesar das intensas disputas entre os distintos projetos societários em torno da hegemonia, os assistentes sociais que atuam neste campo devem buscar construir formas de resistência através de um trabalho 
educativo, de formação de sujeitos políticos críticos e capazes de decifrar a realidade social onde estão inseridos e de forjar formas de construção de uma cultura própria, que corresponda aos seus anseios e necessidades.

É no marco da articulação entre o projeto profissional hegemônico do serviço social e os projetos societários das classes subalternas que situamos a importância do trabalho realizado pelos assistentes sociais no contexto escolar. Sua contribuição incide no campo do processo educativo, ainda que não exclusivamente.

É a particularidade da educação, inscrita como política pública, que amplia horizontes à atuação do assistente social. Particularidade esta que coloca a vida cotidiana dos sujeitos do processo educativo muito próximo dos educadores. Em outras palavras, diferentemente das demais políticas sociais, que são acionadas episodicamente, ou quando a situação vivida pelos sujeitos assim os fazem recorrer a estas, os 'usuários' da política pública de educação são atendidos diariamente pela instituição 'escola', estabelecendo um contato muito próximo entre suas vidas e os educadores.

Esta proximidade a que nos referimos pode e deve ser utilizada pelos profissionais da área da educação no exercício de ações que favoreçam processos emancipatórios e libertadores, ${ }^{7}$ posicionando-se de maneira crítica e fortalecendo o "olhar político" (SARLO, 2005), o olhar de ruptura de todos os envolvidos no processo educativo: famílias, alunos, educadores, comunidade, entre outros.

Conforme Mészáros (2005, p. 48) "Apenas a mais ampla das concepções de educação nos pode ajudar a perseguir o objetivo de uma mudança verdadeiramente radical, proporcionando instrumentos de pressão que rompam a lógica mistificadora do capital".

\footnotetext{
Mészáros (2005, p. 58), ao citar José Martí, esclarece que "a busca da cultura, no verdadeiro sentido do termo, envolve o mais alto risco, por ser inseparável do objetivo fundamental da libertação" e que "ser cultos es el único modo de ser libres".
} 
Portanto, a educação aqui retratada é considerada para além de sua dimensão escolarizada, mas em seu significado ampliado. Enquanto parte constitutiva do campo cultural, torna-se um processo em torno do qual emergem intensas disputas pela hegemonia onde cada sujeito pode contribuir para a mudança ou para a manutenção da ordem vigente.

O projeto de educação burguesa que assistimos hoje não está descolado de um projeto de sociedade mais amplo, construído em favor de uma classe dominante e que visa a manutenção do status quo e a continuidade na formação de uma massa trabalhadora que se reproduza como tal, atendendo aos interesses do capitalismo, não vislumbrando alternativas a esta condição e nem se reconhecendo enquanto classe.

Assim sendo, a luta por um outro projeto educacional também não pode estar desarticulada da luta por um outro projeto societário, que se coloque "para além do capital" (MÉSZÁROS, 2005). E é exatamente no espaço escolar, apesar de todas as adversidades, que os assistentes sociais podem - e devem -, por meio de seu exercício profissional, contribuir para a construção de uma outra forma de sociabilidade, mais justa e igualitária, através de processos educativos amplos, de desocultamento da realidade e de lutas pela construção de uma outra hegemonia, em consonância com o Projeto Ético-Político do Serviço Social.

Submetido em 30 de julho de 2007 e aceito para publicação em 26 de outubro de 2011

\section{Referências}

ALENCAR, M. M. T. de A. Transformaçôes econômicas e sociais no Brasil dos anos 1990 e seu impacto no âmbito da família. In: SALES, Mione Apolinário; MATOS, Maurílio de Castro; LEAL, Maria Cristina. Política Social, família e juventude - uma questão de direitos. São Paulo: Cortez, 2008. 
ALMEIDA, N. L. T. de. Educação pública e o Serviço Social. Revista Serviço Social e Sociedade, n. 63, São Paulo: Cortez, jul.2000a.

CFESS, 2000b.

O Serviço Social na educação. Revista Inscrita, n. 6, Brasília: . Educação. In: Capacitação em Serviço Sociale Política Social. Módulo 03 Política Social. Brasília: CFESS-ABEPSS-Cead-UnB, 2000c.

ANDERSON, P. Nota inicial. In: GENTILLI, P. (org). Pedagogia da exclusão: crítica ao neoliberalismo em educação. 13. ed. Petrópolis: Vozes, 2007.

BRASIL. Lei no 9.394, de 20 de dezembro de 1996. Lei de Diretrizes e Bases da Educação. Estabelece as Diretrizes e Bases da Educação Nacional. Secretaria de Estado da Educação. Brasília: Associação Brasileira de Editores de Livros, 1998.

. Constituição Brasileira. 1988.

BULL, T. G. Trajetória do Serviço Social Escolar de Limeira: construção de uma "educação para além do capital". Dissertação (Mestrado). Programa de PósGraduação em Serviço Social da PUC/SP. São Paulo: PUC/SP, 2010. 180 p. (mimeo.).

CHAUÍ, M. Brasil - Mito fundador e sociedade autoritária. 7. ed. São Paulo: Perseu Abramo, 2007.

COUTO, B. R. O direito social e a assistência social no Brasil: uma equação possivel? São Paulo: Cortez, 2004.

FERNANDES, F. A revolução burguesa no Brasil - ensaio de interpretação sociológica. Rio de Janeiro: Zahar, 1975.

FREIRE, P. Professora sim, tia não: cartas a quem ousa ensinar. São Paulo: Olho d’Água, 1997.

IANNI, O. Questão Social. In: São Paulo em Perspectiva. São Paulo, 5(1), p. 2-10, jan./mar. 1991. . A ideia de Brasil moderno. São Paulo: Brasiliense, 1992.

MARTINS, J. de S. Sobre o modo capitalista de pensar. São Paulo: Hucitec, 1978.

MÉSZÁROS, I. A educação para além do capital. Tradução de Isa Tavares. São Paulo: Boitempo, 2005. 
NUNES, D. G. Educação infantil e o mundo político. In: Katálysis, Florianópolis, 12(1), p. 86-93, jan./jun. 2009.

SARLO, B. Paisagens imaginárias - intelectuais, arte e meios de comunicação. Trad. Rúbia Pratez Goldoni e Sérgio Molina. São Paulo: Editora da Universidade de São Paulo, 2005.

SILVA, T. T. A 'nova' direita e as transformações na pedagogia da política e na política da pedagogia. In: GENTILI, P.; SILVA, T. T. (Orgs.). Neoliberalismo, qualidade total e educação. 5. ed. Petrópolis: Vozes, 1997.

TORRES, Carlos Alberto. Estado, privatização e política educacional: elementos para uma crítica do neoliberalismo. In: GENTILI, Pablo (org.). Pedagogia da exclusão: uma crítica ao neoliberalismo em educação. Petrópolis-RJ: Vozes, 2007. 